08.3,13.4

\title{
Уменьшение работы выхода при гидрогенизации углеродных нанотрубок в плазме водорода
}

\author{
(C) С.В. Булярский ${ }^{1}$, Д.А. Богданова ${ }^{2}$, Е.П. Кицюк ${ }^{3}$, \\ A.В. Лакалин ${ }^{1,2}$, А.А. Павлов ${ }^{1}$, Р.М. Рязанов ${ }^{3}$, \\ А.А. Шаманаев ${ }^{3}$, Ю.П. Шаман ${ }^{3}$ \\ ${ }^{1}$ Институт нанотехнологий микроэлектроники РАН, \\ Москва, Россия \\ ${ }^{2}$ Ульяновский государственный университет, \\ Ульяновск, Россия \\ ${ }^{3}$ НПК „Технологический центр“, \\ Москва, Зеленоград, Россия \\ E-mail: bulyar2954@mail.ru
}

\section{Поступило в Редакцию 5 февраля 2018 г.}

Представлены экспериментальные результаты снижения работы выхода электронов из пучков и массивов вертикально ориентированных углеродных нанотрубок после их гидрогенизации в водородосодержащей плазме. Такая обработка приводит к хемосорбции водорода углеродной нанотрубкой. При этом экспериментально получено уменьшение работы выхода с 4.8 до $3.3 \mathrm{eV}$. Данные результаты подтверждают квантово-механические расчеты, выполненные для одностенных нанотрубок различной хиральности. Расчеты показывают, что уменьшение работы выхода электронов зависит как от свойств нанотрубки, так и от степени пассивации ее водородом.

DOI: 10.21883/PJTF.2018.10.46099.17236

Взаимодействие водорода с углеродными нанотрубками (УНТ) и графеновыми наноструктурами важно с теоретической и практической точек зрения [1-4]. Хемосорбированный водород имеет энергию связи порядка 2.8-3 eV [2], поэтому может быть связан с нанотрубкой даже при температурах существенно выше комнатной. Осуществить процесс гидрогенизации УНТ в термодинамических равновесных условиях (например, путем отжига нанотрубок в атмосфере водорода) очень сложно. Термический отжиг при постоянной температуре практически не приво- 
дит к хемосорбированию водорода. Осуществить хемосорбцию водорода на УНТ можно иным способом. Например, для этого применяют метод электросорбции в водных растворах электролитов [5] либо обработки в плазме водорода [6]. Метод обработки в плазме водорода является более технологичным и вносит меньше загрязнений по сравнению с электросорбцией. Теоретические расчеты показывают, что гидрогенизация УНТ приводит к увеличению эффективности эмиссии электронов с нанотрубок [7], что важно для создания эффективных холодных катодов.

В настоящей работе осуществлена гидрогенизация вертикальных массивов УНТ, а также экспериментально и теоретически показано, что увеличение эффективности эмиссии связано с понижением работы выхода электрона из УНТ.

Массив углеродных нанотрубок синтезировался методом плазмостимулированного химического парофазного осаждения в установке на базе „Plasmalab System 100“ фирмы „Oxford Instruments“ на поверхности кремниевой подложки, на которую предварительно были нанесены пленки титана толщиной $10 \mathrm{~nm}$ и никеля толщиной $2 \mathrm{~nm}$. В процессе синтеза менялось содержание аммиака в газовой смеси c аргоном и водородом. Это приводило к изменению концентрации азота в нанотрубке, которая оценивалась методом оже-спектроскопии. После процесса синтеза УНТ часть образцов подвергалась обработке в водородной плазме в течение 5 и $30 \mathrm{~min}$. Измерения эмиссионных вольтамперных характеристик (BAX) образцов проводились в вакуумной камере при давлении $5 \cdot 10^{-7}$ Torr. Для измерения ВАХ был использован программируемый двухканальный источник-измеритель В2912А фирмы Agilent. Данный прибор оптимизирован для измерения слаботочных сигналов вплоть до $10^{-15} \mathrm{~A}$ и оснащен специальными экранированными триаксиальными разъемами с функцией компенсации сверхмалых токов. $\mathrm{BAX}$ массивов УНТ сразу после синтеза и после обработки в плазме водорода приведены на рис. 1.

Эксперимент показывает, что после гидрогенизации величина порогового напряжения уменьшается. Вольт-амперные характеристики были перестроены в координатах Фаулера-Нордгейма $\ln \left(I / U^{2}\right)=f(1 / U)$. Изменение наклона данных ВАX указывает на то, что величина работы выхода электронов из нанотрубок, обработанных в плазме водорода, уменьшается. Концентрация азота в нанотрубках оказывает влияние на эмиссионные токи помимо гидрогенизации их водородом (рис. 1).

Письма в ЖТФ, 2018, том 44, вып. 10 


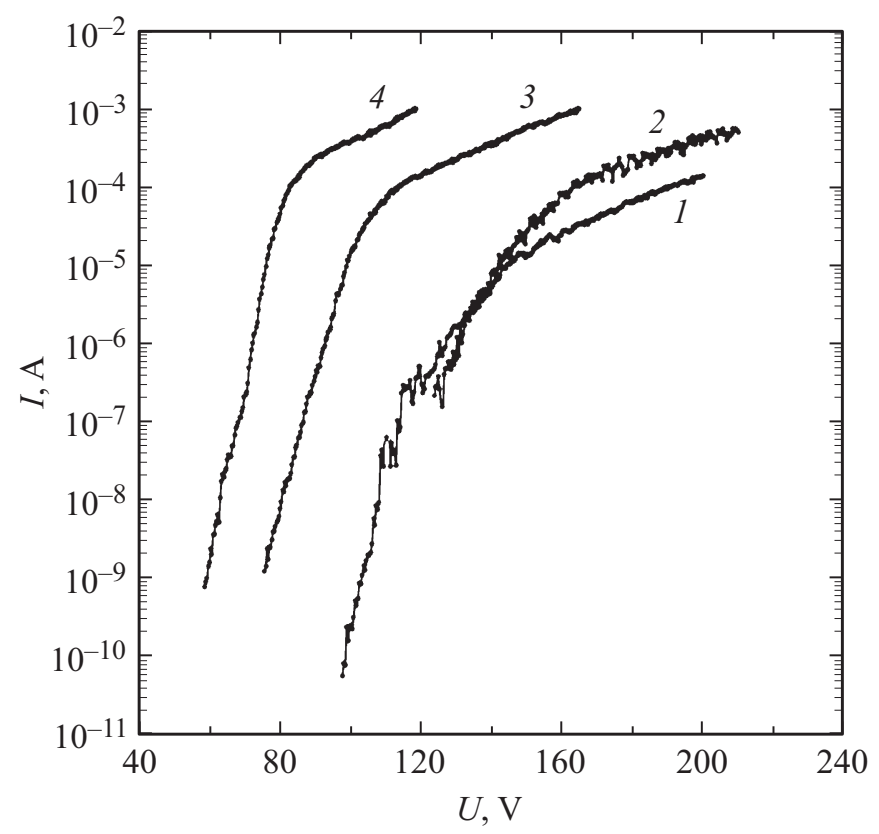

Рис. 1. Эмиссионные вольт-амперные характеристики образцов углеродных нанотрубок, синтезированных при температуре $780^{\circ} \mathrm{C}$. 1,2 - до обработки в плазме водорода, 3,4 - после обработки в плазме водорода. 1,3 концентрация азота в нанотрубках $2.5 \%, 2,4-6 \%$.

Определить работу выхода электронов возможно только в случае одиночной нанотрубки, когда напряженность поля вблизи ее конца, испускающего электроны, можно вычислить точно [8]. Будем считать, что работа выхода электронов из одиночной нанотрубки равна $4.8 \mathrm{eV}[9]$. При этом можно ввести понятие коэффициента усиления электрического поля как отношение рассчитанной величины поля у конца нанотрубки к средней напряженности поля между катодом и анодом эмиссионной системы. Массив УНТ состоит из нанотрубок различной длины; кроме того, соседние нанотрубки экранируют друг друга. В связи с этим коэффициент усиления поля при измерении эмиссионных токов массива должен иметь иное значение, чем для одиночной нанотрубки.

Письма в ЖТФ, 2018, том 44, вып. 10 


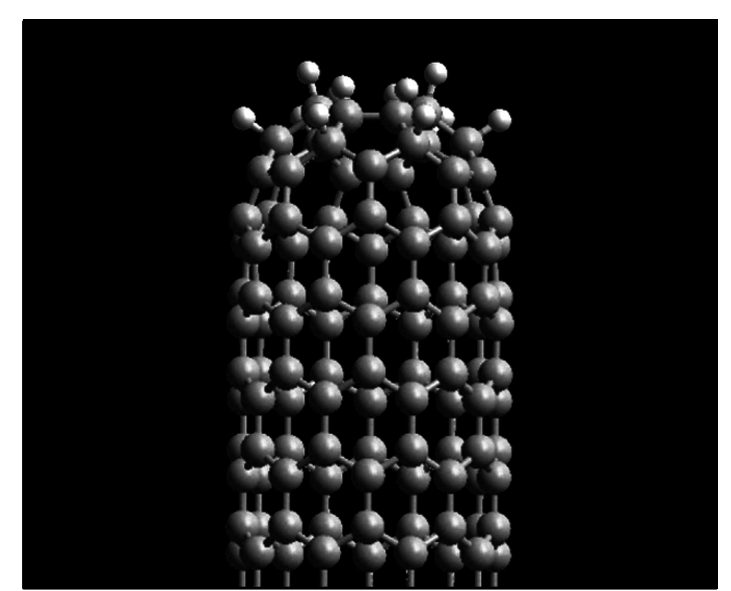

Рис. 2. Модель покрытия системы $\mathrm{C}_{60}+(9,0)$ двенадцатью адатомами водорода.

Однако нет физических причин изменения величины работы выхода электронов. Полагаем, что у нанотрубок в массиве, так же как и у одиночных нанотрубок, работа выхода электронов одинакова и сразу после синтеза равна $4.8 \mathrm{eV}$. Можно ввести эффективный коэффициент усиления электрического поля у концов УНТ в массиве таким образом, чтобы при вычислениях работа выхода электронов равнялась указанному значению. При сравнении экспериментальной ВАХ массива, обработанного в плазме водорода, с ВАХ исходного (необработанного) массива (рис. 1) было найдено, что работа выхода после обработки в плазме снижается до значения $3.3 \mathrm{eV}$.

Для того чтобы оценить перспективы применения описанной выше технологии снижения работы выхода, было проведено квантовохимическое моделирование нанотрубок с закрытым полуфуллереном концом при различных плотностях водородного покрытия нанотрубок. В настоящей работе рассматривалась хемосорбция только на полуфуллерене. Поэтому под плотностью покрытия подразумевается отношение числа адсорбированных на полуфуллерен атомов водорода к полному числу атомов полуфуллерена. Минимальное покрытие - два адатома водорода на полуфуллерен, максимальное - полное покрытие полуфуллерена. При каждой плотности покрытия выбирались центры ад-

Письма в ЖТФ, 2018, том 44, вып. 10 


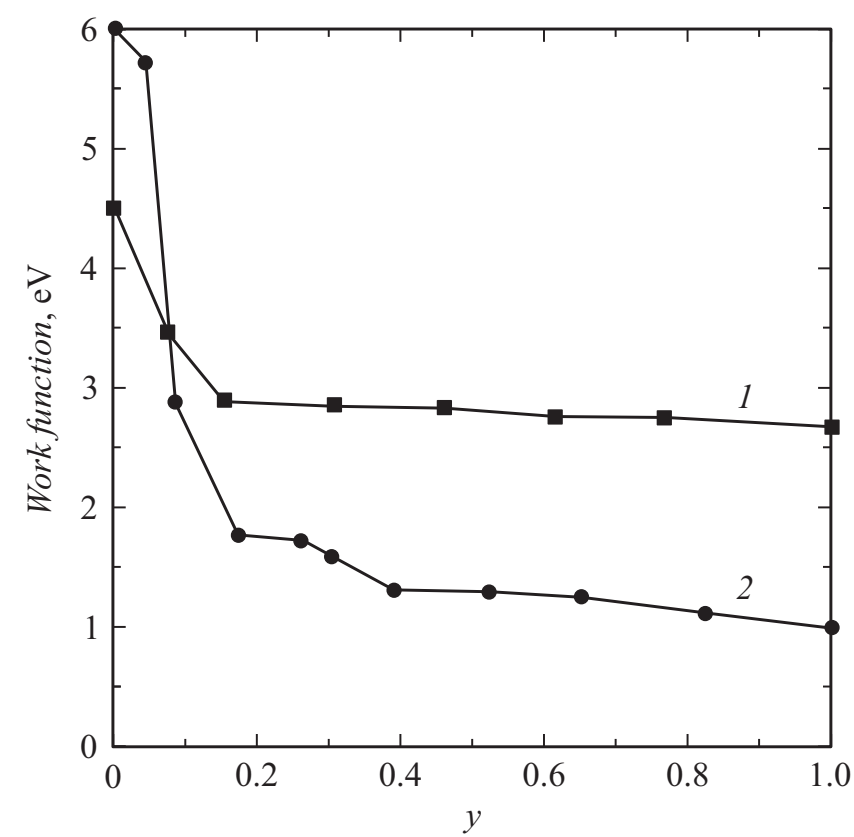

Рис. 3. Работа выхода как функция плотности водородного покрытия $(y)$ для различных систем. $1-\mathrm{C}_{60}+(9,0), 2-\mathrm{C}_{80}+(6,6)$.

сорбции, соответствующие наиболее устойчивым конформациям после оптимизации геометрии. Расчет проводился полуэмпирическим методом PM3 (параметризированная модель, версия 3). Для моделирования были выбраны одностенные УНТ длиной в шесть элементарных ячеек, закрытые с одного конца полуфуллеренами: $\mathrm{C}_{80}+(6,6)$ и $\mathrm{C}_{60}+(9,0)$. При моделировании хемосорбированный водород размещали парами (рис. 2), так как данный вариант размещения является энергетически более выгодным $[1,2]$. Рассчитанная по энергетическому спектру работа выхода как функция плотности водородного покрытия представлена на рис. 3.

Можно видеть, что работа выхода убывает с увеличением водородного покрытия от 6 до $1 \mathrm{eV}$ для системы $\mathrm{C}_{80}+(6,6)$ и от 4.5 до $2.7 \mathrm{eV}$ для системы $\mathrm{C}_{60}+(9,0)$. Данное явление связано с тем, что

Письма в ЖТФ, 2018, том 44, вып. 10 
при хемосорбции водорода на полуфуллерене происходит изменение электростатического потенциала нанотрубки. У системы появляется дополнительный дипольный момент. Это приводит к снижению работы выхода.

Таким образом, экспериментально исследованы пучки и вертикальные массивы многостенных УНТ, подвергнутые обработке в плазме водорода. Эксперимент и квантово-механические расчеты указывают на то, что такая обработка в плазме водорода приводит к его хемосорбции, в результате чего работа выхода уменьшается. При этом экспериментально получено уменьшение работы выхода с 4.8 до $3.3 \mathrm{eV}$. Данные результаты подтверждаются квантово-механическими расчетами, выполненными для одностенных нанотрубок различной хиральности. Показано, что уменьшение работы выхода обусловлено изменением потенциала конца нанотрубки, покрытого водородом, причем величина этого уменьшения зависит как от свойств нанотрубки, так и от степени заполнения ее водородом. Полученные результаты могут быть использованы в технологии создания автоэмиссионных элементов наноэлектроники.

Работа поддержана Министерством образования и науки РФ (проект № 16.2773.2017/4.6).

\section{Список литературы}

[1] Булярский C.B. Углеродные нанотрубки: технология, управление свойствами, применение. Ульяновск: Стрежень, 2011. 432 с.

[2] Bulyarskiy S., Saurov A. Doping of carbon nanotubes. Springer, 2017. 187 p.

[3] Peng X., Tang F., Copple A. // J. Phys.: Condens. Matter. 2012. V. 24. P. 075501.

[4] Kvashnin D.G., Sorokin P.B., Bruning J.W., Chernozatonskii L.A. // Appl. Phys. Lett. 2013. V. 102. P. 183112.

[5] Lota G., Lota K., Kapica R., Tyczkowski J., Fic K., Frackowiak E. // Int. J. Electrochem. Sci. 2015. V. 10. P. 4860-4872.

[6] Zhang P., Qi P., Wang X., Lu Y., Mann D., Li X. // J. Am. Chem. Soc. 2006. V. 128. P. 6026-6027.

[7] Yaghoobi P., Alam K., Walus K., Nojeh A. // Appl. Phys. Lett. 2009. V.95. P.262102.

[8] Лакалин А.В., Павлов А.А., Шаманаев А.А. // Микроэлектроника. 2017. Т. 46. B. 1. C. 14-20.

[9] Елецкий А.В. // УФН. 2010. Т. 180. В. 9. С. 897-930.

Письма в ЖТФ, 2018, том 44, вып. 10 